had been successfully treated, $27.8 \%$ had metastasis, $5.6 \%$ had died. There was no significant difference in SLEDAI between patients with cancer and patients without. Whereas malignancy is correlated to longer disease duration $(p=0.01)$ and older age of SLE onset with significant difference $(p=$ $0.001)$.

Conclusion: Although we have detected an increasing incidence of cancer in SLE patients in comparison to normal population, our study didn't find a signficant correlation between SLE disease activity and the risk of cancer. We should closely observe SLE patients with old age at onset and/or long disease duration because of their higher risk for cancer development.

References:

[1] Bernatsky S, Ramsey-Goldman R, Joseph L, et al (2014). Lymphoma risk in systemic lupus: effects of disease activity versus treatment. Ann Rheum Dis, 73, 138-42.

[2] Hochberg MC (1997). Updating the American College of Rheumatology revised criteria for the classification of systemic lupus erythematosus. Arthritis Rheum, 40, 1725.

[3] Bombardier C, Gladman DD, Urowitz MB, Caron D, Chang CH (1992) Derivation of the SLEDAI. A disease activity index for lupus patients. The Committee on Prognosis Studies in SLE. Arthritis Rheum:630-640.

Disclosure of Interests: None declared

DOI: 10.1136/annrheumdis-2020-eular.5044

\section{AB0395 \\ SYSTEMIC LUPUS ASSOCIATED MACROPHAGE ACTIVATION SYNDROME - A SINGLE CENTRE EXPERIENCE FROM INDIA}

N. Acharya ${ }^{1}$, S. Jha ${ }^{1}$, D. Mishra ${ }^{1}$, A. Chattopadhyay ${ }^{1}$, S. Jain ${ }^{1}$, S. K. Sharma ${ }^{1}$, A. Sharma ${ }^{1}$, S. Jain ${ }^{1}$, V. Dhir ${ }^{1} .{ }^{1}$ Post Graduate Institute of Medical Education and Research, Division of Rheumatology, Department of Internal Medicine, Chandigarh, India

Background: Macrophage activation syndrome (MAS) is a potentially fatal complication of systemic lupus erythematosus (SLE).(1) Overlapping clinical features of SLE activity with MA makes it a clinical diagnosis. There is limited data from developing countries like India.

Objectives: To study the clinical features, treatment, and outcomes in SLE-MAS.

Methods: This single-centre, retrospective study included patients fulfilling SLICC 2011 criteria for SLE, admitted from January 2017 to November 2019, and diagnosed as MAS by a team of attending physicians. Their demographic and clinical data, treatment, and outcomes were recorded. $\mathrm{H}$ score and SLEDAI were calculated. Patients were assessed for HLH classification criteria (2004) and preliminary diagnostic criteria for MAS in childhood SLE (cSLE).

\section{Table 1. Patient characteristics}

\begin{tabular}{lc}
\hline Characteristic & $\mathrm{N}=16$ \\
\hline Age (years) & $26(19.5-30)$ \\
Duration of symptoms (days) & $60(18.7-90)$ \\
Fever & $16(100)$ \\
Pancreatitis & $1(6.3)$ \\
Renal & $7(43.8)$ \\
Neurological & $7(43.8)$ \\
Myocarditis & $6(37.5)$ \\
Hepatomegaly & $7(43.8)$ \\
Splenomegaly & $3(18.8)$ \\
Lymphadenopathy & $12(75)$ \\
Anaemia & $16(100)$ \\
Leukopenia & $13(82)$ \\
Thrombocytopenia & $14(88.2)$ \\
Coagulopathy & $7(43.8)$ \\
Concomitant infection & $3(18.8)$ \\
H score & $222(193-254)$ \\
cSLE-MAS diagnostic criteria & $16(100 \%)$ \\
HLH 2004 ( $\geq 5)$ & $7(43.8)$ \\
Corticosteroids & $16(100 \%)$ \\
Cyclophosphamide & $8(50 \%)$ \\
Intravenous immunoglobulin & $2(12.5 \%)$ \\
Cyclosporine & $6(37.5 \%)$ \\
Death & $4(25 \%)$ \\
\hline All &
\end{tabular}

All data presented as $\mathrm{n}(\%)$ and median (IQR)

cSLE-MAS - Childhood systemic lupus erythematosus - Macrophage activation syndrome, $\mathrm{HLH}$ - Hemophagocytic lymphohistiocytosis
Results: Sixteen patients (median age - 26 years, 15 females) were included. Twelve patients (75\%) had MAS as the initial presentation of SLE. The common clinical features were fever (100\%) and cytopenias (100\%). The mean duration of symptoms was 60 days. The most frequent biochemical abnormalities were high ferritin (>500 ng/ml, 100\%) and elevated transaminases $(100 \%$, aspartate transaminase $>$ alanine transaminase). Common complications were renal $(43.8 \%)$, neurological $(43.8 \%)$, and coagulopathy $(43.8 \%)$. Seven and 16 patients fulfilled the HLH 2004 and cSLE - MAS preliminary criteria, respectively. The median $\mathrm{H}$ score was 222 , giving a cumulative probability of $96 \%$. All the patients received high-dose steroids. Cyclophosphamide pulse and cyclosporine were administered to 8 $(50 \%)$ and $6(37.5 \%)$ patients respectively. There were four $(25 \%)$ in-hospital mortalities.

Table 2. Laboratory features

\begin{tabular}{lc}
\hline Parameter & $\mathbf{N}=\mathbf{1 6}$ \\
\hline Haemoglobin (g/dL) & $6.9(5.7-7.8)$ \\
Total leucocyte count (cells/mm3) & $1400(1025-3175)$ \\
$<1000$ & $3(18.8)$ \\
$1000-2500$ & $9(56.3)$ \\
$2500-4000$ & $1(6.3)$ \\
Platelet (cells/mm3) & $57500(23500-95250)$ \\
$<20000$ & $3(18.8)$ \\
$20000-50000$ & $3(18.8)$ \\
$50000-1$ lac & $8(50)$ \\
Serum ferritin $>500 \mathrm{ng} / \mathrm{ml}$ & $16(100 \%)$ \\
Fibrinogen & $2.48(1.6-4)$ \\
Triglycerides (mg/dL) & $375(294-470)$ \\
AST/ALT (U/L) & $0.8(0.3-1.4)$ \\
Procalcitonin (pg/mL) & $1674(1081-2184)$ \\
Lactate dehydrogenase (U/L) & $61(44-69)$ \\
Erythrocyte sedimentation rate (mm in $1^{\text {st }}$ hour) & $36(6.3-52)$ \\
C- reactive protein (mg/L) & $14(87.5)$ \\
Bone marrow examination & $5(32.5)$ \\
Increased histiocytes with hemophagocytosis & \\
\hline
\end{tabular}

All data presented as $\mathrm{n}(\%)$ and median (IQR)

ALT - Alanine transaminase, AST - Aspartate transaminase

Conclusion: Fever, cytopenia, high ferritin, and elevation of transaminases were the commonest features in this series of SLE-MAS. SLE-MAS carried a high mortality $(25 \%)$ despite aggressive treatment.

\section{References:}

[1] Gavand P-E, Serio I, Arnaud L, Costedoat-Chalumeau N, Carvelli J, Dossier $A$, et al. Clinical spectrum and therapeutic management of systemic lupus erythematosus-associated macrophage activation syndrome: A study of 103 episodes in 89 adult patients. Autoimmun Rev. 2017;16(7):743-9.

Acknowledgments: NONE

Disclosure of Interests: None declared

DOI: 10.1136/annrheumdis-2020-eular.5703

\section{AB0396 DIAGNOSTIC PROTOCOL INCLUDING MINIMALLY INVASIVE MINOR SALIVARY GLANDS BIOPSY IN SJÖGREN'S SYNDROME IN A SPANISH REFERENCE CENTER}

J. Álvarez Troncoso ${ }^{1}$, C. M. Oñoro López ${ }^{1}$, C. Soto Abánades ${ }^{1}$, E. Ruiz Bravo ${ }^{2}$, L. Ramos Ruperto ${ }^{1}$, L. Blasco Santana ${ }^{2}$, R. Sorriguieta Torre ${ }^{1}$, Á. Robles Marhuenda ${ }^{1}$, E. Martínez Robles ${ }^{1}$, A. Noblejas Mozo ${ }^{1}$, J. J. Rios ${ }^{1}$, F. Arnalich

Fernández'. ${ }^{1}$ Hospital Universitario La Paz, Department of Internal Medicine, Madrid, Spain; ${ }^{2}$ Hospital Universitario La Paz, Pathological Anatomy, Madrid, Spain

Background: Sjögren's syndrome (SjS) is a systemic autoimmune disease with a broad clinical presentation from dry syndrome to systemic extraglandular manifestations. The diagnosis can be complex since none of the markers, except anti-Ro, is sufficiently sensitive or specific. Although, minor salivary glands biopsy (MSGB), Schirmer's test and unstimulated whole salivary flows (UWSF) are the hallmark for the diagnosis of this entity, its use is not widespread in some centers.

Objectives: The aim of the study was to analyze the usefulness and safety of the diagnostic protocol for the classification of SjS and the immunological and analytical markers in dry syndrome due to SjS. 